\title{
COMPILATION OF A GENERAL PRACTITIONER DATABASE
}

Michael Mira, Director, Division of GP,

Central Sydney Area Health Service

Elizabeth Ryman, Acting Clinical Services Co-ordinator and Chairman, GP Liaison Committee, Royal Prince Alfred Hospital

Peter D Leslie, Systems Analyst

Michael J Fett, Director, Public Health Unit for Central and Southern Sydney

\section{SYNOPSIS}

General practitioners provide a substantial proportion of health care to the community but often practise in isolation. A database of local general practitioners (GPs) may be used to improve patient care and enhance the recognition of the role of the GP by facilitating communication between GPs and other health professionals. Development and utilisation of a database listing all GPs in a Health Service Area with a population of 330,000 is described.

Data from medical provider files, pharmaceutical industry and local general practitioner association membership lists, lists of GPs attending seminars and the business telephone directory were combined and each GP identified was contacted and asked to provide information including gender, billing methods, practice hours and languages spoken.

The number of GPs in active practice and their response rates to individual questions were determined. The utilisation of the database is reported.

Combination of the five data sources yielded 651 possible GPs; 415 were found to be in active practice. GPs were willing to provide practice information; the response rate to each question was more than 90 per cent.

Compilation of a local database of general practitioners is relatively easy and inexpensive. Such a database is well utilised as a means of communication between GPs and other health professionals. Should a representative range of areas compile such databases this information could be combined to provide an accurate sampling frame for research.

\section{INTRODUCTION}

About half the medical services used by the population are provided by general practitioners ${ }^{1}$ yet there have been few attempts to integrate GP services with those provided directly by State and Federal governments. It has been suggested that GPs are becoming increasingly isolated from other health professionals ${ }^{2}$.

A recent analysis of available listings of GPs has found there is no single listing of GPs which is accurate or readily available ${ }^{3}$. The authors discussed how an accurate listing was necessary for general practice research but did not consider how such a database could enhance patient care.

The Central Sydney Health Service has collected data on all GPs actively practising in the Area. The database was derived to:

$$
\begin{array}{l|l}
\text { facilitate communication between Health Service } \\
\text { staff and local GPs and between the GPs; } \\
\text { allow referral of hospital patients without a family } \\
\text { doctor to appropriate GPs; and } \\
\text { provide a sampling frame for research projects } \\
\text { involving local GPs. }
\end{array}
$$

In this report the methods of database compilation are described and the use of the database over a six-month
FIGURE 1

FORMATTED OUTPUT FROM DATABASE

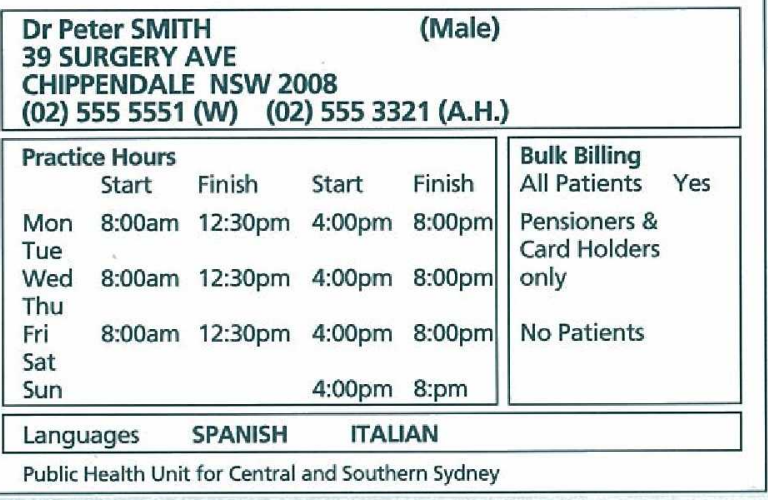

period is discussed.

The database was compiled in the following way:

1. Data from five sources were pooled. The sources were the Medical Provider File, a pharmaceutical industry list, the membership list of the Central Sydney GP Association, attendance lists from the Royal Prince Alfred Hospital seminar program and the business telephone directory.

2. A questionnaire was sent to each address identified from the five sources. Practice information was sought and the general practitioners were asked whether they wished to receive referrals from the Health Service.

3. Non-responders were telephoned when a number was available. Where no listing was found in the business or private telephone directories, the nearest general practice was contacted and the receptionist questioned about the existence of nearby GPs.

Data were collected from the questionnaire or, in the case of doctors who did not respond to the written approach, by telephone.

A 'user friendly' program for IBM-compatible microcomputers was written using Clipper to allow data entry and report generation by clerical staff. Less than one hour of staff training is required. Data are stored in dBASE format and may be manipulated in a variety of ways using dBASE or may be written to a range of formats.

The software allows automatic generation of address labels and also formatted output suitable for photographic reproduction. An example of one entry is shown in Figure 1. Three such entries are produced on each A4 page. The entries are sorted alphabetically on the doctor's last name. For purposes of patient referral two indexes are provided: one based on language spoken by the doctor and the other based on the suburb of practice. Copies of the software are available from the authors at minimal cost.

Pooling of the data sources gave a total of 651 possible general practitioners. A total of 224 doctors responded to the mailed questionnaire; 210 indicated they were prepared to accept referrals from the Area Health Service and 22 provided practice information but did not want patients referred. The remaining 427 names were investigated and $191 \mathrm{GPs}$ in active practice were identified, giving a total of 415 GPs in 281 practices.

The availability of a comprehensive database has been 


\section{Gastroenteritis}

\section{Continued from page 77}

These events took place on two consecutive days of one weekend. Clinical features of the illness were suggestive of infection with calicivirus or a related virus. However, no clinical specimens were obtained for pathological confirmation and it was not possible to test food or water samples for the presence of pathogenic viruses.

Although the outbreak described in this report was a relatively minor one, the investigation of a much larger outbreak is likely to be hampered by the same difficulties. A mechanism to give the NSW public health network rapid access to laboratory services for virological examination of water and foodstuffs is needed to aid the investigation of future outbreaks.

\section{ACKNOWLEDGMENT}

We are grateful to Dr Alan Stark, University of NSW, for statistical advice and helpful comments on the manuscript.

1. Cubitt WC. The candidate caliciviruses. In: Bock E, Whelan J (eds). Novel diarrhoea viruses (Ciba Foundation symposium 128). Chichester $1987 ; 136-137$.

2. Pickering LK, Bartlett AV, Reves RR, Morrow A. Asymptomatic excretion of rotavirus before and after rotavirus diarrhoea in children in day care centers. J Pediatr 1988; 112:361-365.

3. Centers for Disease Control. Viral agents of gastroenteritis: public health importance and outbreak management. MMWR 1990; 39(RR-5); 6-7.

4. Birch C, Gust I. Sewage pollution of marine waters: the risks of viral infection. Med J Aust 1989; 151:609-610.

5. Ellender RD, Anderson JB, Dunbar RB. Role of sediment in the persistence and transport of enteric viruses in the estuarine environment. In: Rao CV, Melnick JL, eds. Human viruses in sediments, sludges and soils. Florida, CRC Press 1987; 37-55.

\section{PUBLIC HEALTH EDITORIAL STAFF}

The Bulletin's editorial advisory panel is as follows: Dr Sue Morey, Chief Health Officer, Public Health Division, NSW Health Department; Professor Stephen Leeder, Director, Department of Community Medicine, Westmead Hospital; Professor Geoffrey Berry, Head Department of Public Health, University of Sydney; Dr Christine Bennett, General Manager, Royal Hospital for Women; Dr Michael Frommer, Deputy Director

Epidemiology and Health Services Evaluation Branch, NSW Health Department; Ms Jane Hall, Director, Centre for Health Economics Research and Evaluation; and Mr Michael Ward, Manager, Health Promotion Unit.

The editor is Dr George Rubin, Director, Epidemiology and Health Services Evaluation Branch, NSW Health Department.

The Bulletin aims to provide its readers with population health data and information to motivate effective public health action. Articles, news and comments should be 1,000 words or less in length and include the key points to be made in the first paragraph. Please submit items in hard copy and on diskette, preferably using WordPerfect 5.1, to the editor, Public Health Bulletin Locked Mail Bag 961, North Sydney 2059. Facsimile (02) 3919232.

Design - Health Public Affairs Unit, NSW Health Department. Suggestions for improving the content and format of the Bulletin are most welcome.

Please contact your local Public Health Unit to obtain copies of the NSW Public Health Bulletin.

\section{General practice database}

\section{Continued from page 75}

widely publicised and the database has been used for a range of purposes. These include:

Production of a document listing doctors willing to receive referrals from the Area Health Service. When a district hospital Accident and Emergency Department was closed, the database was used to provide residents with a listing of GPs in their area. The Area Health Service sends a monthly newsletter to all GPs. An average of four Area Health Service departments or community service groups and two GPs a month request information be included with the newsletter.

- The Public Health Unit produces a bulletin to inform GPs of infectious disease outbreaks, including reports from the local general practice sentinel surveillance network. At the start of an outbreak of hepatitis A the PHU used the database to contact all GPs in the Area. They received information within 72 hours. The database has been used as a sampling frame for several research studies. Community health and health promotion professionals have used the database to contact GPs serving particular ethnic groups or geographical areas.

A profile of general practice in Central Sydney has been produced to assist in planning the provision of services in the Area.

\section{DISCUSSION}

A comprehensive database of GPs has a wide range of uses at a local level, many of which may enhance the health of the community by allowing timely and locally appropriate information to be disseminated to practitioners.

The frequent requests for information to be sent to GPs indicate a desire, on the part of Area Health Service staff and community groups, to liaise with family doctors in order that available services be used most efficiently. This communication is not just one way, as the newsletter is also circulated to more than 400 salaried and visiting medical staff in the Area and to each clinical department at RPAH, thus increasing awareness of the activities of local GPs.

Compilation of a database at a local level is not particularly time-consuming or expensive. The estimated cost of compiling the database for Central Sydney (which has a population of 330,000 ), excluding the cost of software development but including all data collection costs and salaries, was $\$ 4,000$.

\section{ACKNOWLEDGMENTS}

The authors would like to acknowledge Marina Helsdingen, Sumi Nair, Sarda Borusch and Lorraine Winchester who assisted with data collection and data management. The GP Liaison Committee of Royal Prince Alfred Hospital has provided invaluable advice and support.

1. Deeble J. Medical services through Medicare. Canberra: National Health Strategy Unit, Department of Health, Housing and Community Services, Feb 1991. (NHS background paper No 2.)

2. Douglas RM. General practice financing: report of a 'think tank' Med J Aust 1992; 156:38-42.

3. Saltman DC, Mant A. General practitioner databases in Australia. Med J Aust 1992; 156:16-20. 